\title{
Formas de sociabilidad y representaciones sobre las juventudes en Argentina a comienzos del siglo XX. El modelo de la Asociación Cristiana de Jóvenes en Buenos Aires ${ }^{1}$
}

\author{
Luciana Carreño ${ }^{2}$
}

Recibido: 22 de julio de 2020 / Aceptado: 23 de julio de 2021

Resumen. El artículo estudia la circulación de modelos de sociabilidad y representaciones sobre las juventudes en Argentina a través del análisis de la Asociación Cristiana de Jóvenes en la ciudad de Buenos Aires. Tras su organización, esta asociación de origen angloamericano buscó extender su convocatoria, orientada originalmente al elemento estudiantil universitario, hacia los sectores populares. Desde esa proyección, sus actividades contribuyeron a colocar a las juventudes dentro de la agenda pública. Las representaciones sobre las juventudes, configuradas de acuerdo con distintos estereotipos de masculinidad, se analizaron a través de un entramado que incluye la circulación trasnacional de saberes, las apropiaciones por parte de grupos de intelectuales en el marco local y del contraste con las identidades de quienes portaban o resistieron esas representaciones.

Palabras clave: Juventudes; Representaciones; Sociabilidad; Asociación Cristiana de Jóvenes; Masculinidad; Argentina.

\section{[en] Forms of sociability and representations of youths in Argentina at the} beginning of the $20^{\text {th }}$ century. The model of the Young Men's Christian Association in Buenos Aires

\begin{abstract}
This article studies the circulation of representations and models of youth sociability in Argentina by analysing the Young Men's Christian Association in the city of Buenos Aires. Once consolidated, this organization of Anglo-American origin looked to extend its call, from the university student body to which it was originally oriented towards the popular sectors. This projection of its activities contributed to placing youths on the public agenda. The youths' representations, that were configured according to different stereotypes of masculinity, were analyzed through a framework that includes the transnational circulation of knowledge, appropriations by groups of intellectuals in the local setting and a through a contrast with the identities of the agents who bore or resisted these representations. Keywords: Youths; Representations; Sociability; Young Men's Christian Association; Masculinity; Argentina.
\end{abstract}

1 Este trabajo se enmarca en el proyecto posdoctoral "Sociabilidades juveniles en torno a la Reforma Universitaria y la experiencia democrática. Los modos de intervención pública y universitaria del asociacionismo estudiantil de la Universidad de Buenos Aires (1912-1930)" financiado por el Consejo Nacional de Investigaciones Científicas y Técnicas. Asimismo, forma parte del proyecto "Universitarios en Argentina. Proyectos científicos y prácticas académicas, culturales y políticas, entre el siglo XX y los inicios del XXI", financiado por el Departamento de Ciencias Sociales de la Universidad Nacional de Quilmes. Agradezco los comentarios y aportes realizados a este trabajo en las evaluaciones anónimas para la revista Cuadernos de Historia Contemporánea.

2 Consejo Nacional de Investigaciones Científicas y Técnicas, Centro de Estudios en Historia, Cultura y Memoria, Departamento de Ciencias Sociales, Universidad Nacional de Quilmes.

E-mail: lcarreno1@uvq.edu.ar 
Sumario. Introducción. 1. La difusión de un modelo. La fundación de la Asociación Cristiana de Jóvenes en Argentina. 2. La definición de una convocatoria y de un "campo juvenil" en la agenda pública. 3. Modalidades de intervención pública de las juventudes cristianas. 4. Conclusión 5. Referencias bibliográficas.

Cómo citar: Carreño, L. (2021). Formas de sociabilidad y representaciones sobre las juventudes en Argentina a comienzos del siglo XX. El modelo de la Asociación Cristiana de Jóvenes en Buenos Aires. Cuadernos de Historia Contemporánea, Vol. 43, 145-165.

\section{Introducción}

En las últimas décadas los estudios sobre historia de las juventudes han ampliado sus alcances y temas de indagación. El análisis de las culturas y movimientos juveniles luego de la Segunda Guerra Mundial, predominante en la historiografía sobre el tema, se ha visto enriquecido con nuevas investigaciones que han profundizado en la relevancia que comenzaron a adquirir estos sectores dentro de una serie de cambios desde finales del siglo XIX y los procesos de industrialización en el mundo occidental. A partir de ese periodo, los trabajos relativos al ámbito europeo y nortemericano han dado cuenta de cómo las juventudes pasaron a ser protagonistas y objeto de una serie medidas desde distintos campos institucionales (los sistemas educativos, judiciales y correccionales, los servicios militarles obligatorios, etc.); específicas prácticas de consumo y de ocio; nuevos tipos de militancia política-cultural en el periodo de entreguerras, entre otros temas. ${ }^{3}$

Esta tendencia se registra, aunque en menor medida, en América Latina, en donde el análisis sobre las juventudes en el periodo de finales del siglo XIX y la primera mitad del siglo XX ha comenzado a desarrollarse en estrecha relación con los estudios, más constituídos, sobre las infancias. Estas producciones historiográficas han destacado el papel fundamental que ocuparon principalmente las infancias, y como extensión las juventudes, como objeto de políticas públicas y de iniciativas de la sociedad civil, en tanto grupos de mayor relevancia para los proyectos construcción de las naciones latinoamericanas. ${ }^{4}$ Asimismo, desde otra perspectiva no centrada específicamente en los cambios sociales y culturales que repercutían en prácticas y representaciones sobre lo juvenil, el estudio de las juventudes se ha enfocado principalmente en los movimientos estudiantiles a partir de ese periodo. ${ }^{5}$ Para el caso argentino, los trabajos

3 Véanse los análisis historiográficos de Heilbronner, Oded: "From a Culture for Youth to a Culture of Youth: Recent Trends in the Historiography of Western Youth Cultures", Contemporary European History, 4 (2008), pp. 575-591 y Souto Kustrín, Sandra: "Historiografía y jóvenes: la conversión de la juventud en objeto de estudio historiográfico", Páginas, 22 (2018), pp. 16-38.

4 Para América Latina se destacan los aportes de Carreras, Sandra y Barbara Potthast (eds.): Entre la familia, la sociedad y el Estado. Niños y jóvenes en América Latina (siglos XIX-XX), Madrid-Frankfurt, IberoamericanaVervuert, 2005. Específicamente para los casos uruguayo, mexicano y argentino: Barrán, José Pedro: Historia de la sensibilidad en el Uruguay, Montevideo, Ediciones de la Banda Oriental, 2009. (1ºd. 1994); Pérez Islas, José Antonio y Urteaga Castro- Pozo, Maritza (coords.): Historias de los jóvenes en México. Su presencia en el siglo XX, México D.F, Instituto Mexicano de la Juventud, 2004 y Bontempo, María Paula y Bisso, Andrés (eds.): Infancias y juventudes en el siglo XX: política, instituciones estatales y sociabilidades, Buenos Aires, Teseo Press, 2019. Desde 2015, los estudios sobre las infancias cuentan con una expresión institucional en la Red de Estudios de Historia de las Infancias en América Latina (REHIAL). Véase Lionetti, Lucía, Cosse, Isabella y Zapiola, María Carolina (comps.): La historia de las infancias en América Latina, Tandil, Universidad Nacional del Centro de la Provincia de Buenos Aires, 2018.

5 Dentro esta línea figura el análisis pionero de Portantiero, Juan Carlos: Estudiantes y política en América Latina. El proceso de la Reforma Universitaria (1918-1938), México, Siglo XXI, 1978. Se destaca asimismo la 
sobre la Reforma Universitaria de 1918 han destacado la relevancia de ese movimiento en la definición de un nuevo papel político e intelectual que pasaban a ocupar las juventudes universitarias en el contexto político, social e ideológico marcado por las repercusiones de la Gran Guerra y la Revolución rusa, la primera experiencia democrática electoral (aunque restringida al sufragio universal-masculino desde los 18 años) y el ciclo de protestas obreras sucedidas en el país entre 1919 y $1921 .{ }^{6}$

A partir de este marco historiográfico, el artículo propone contribuir al estudio de las juventudes en Argentina desde un abordaje que indaga sobre las representaciones y prácticas civiles y profesionales que se elaboraban sobre estos sectores en las primeras décadas del siglo XX, sin desconsiderar paralelamente las experiencias culturales y las formas de intervención política de quienes se convocaba o se identificaban con esa condición. Para lo cual, se centra en reconstruir las representaciones y el modelo de sociabilidad juvenil que llevó a cabo la Asociación Cristiana de Jóvenes (ACJ) en la ciudad de Buenos Aires en las tres primeras décadas del siglo XX. ${ }^{7}$ A partir de su fundación en Londres en 1844, la Young Men's Christian Association (YMCA) contó con una amplia proyección internacional, la cual se concretó especialmente a través de la difusión de este modelo desde Estados Unidos. Fue precisamente el formato estadounidense el que más influyó en la creación y desarrollo de la filial argentina de la YMCA, la cual fue fundada en 1902 con el nombre de Asociación Cristiana de Jóvenes, por miembros de la comunidad protestante en Buenos Aires.

Se parte de la consideración de que las asociaciones constituyen vías específicas y diferenciadas para estudiar las diversas formas de sociabilidad y representaciones sobre las juventudes que circularon en este periodo de modo paralelo al sistema educativo y a otros marcos institucionales. ${ }^{8}$ Así, a diferencia de otras interpelaciones dirigidas

obra de Biagini, Hugo: La contracultura juvenil. De la emancipación a los indignados, Buenos Aires, Capital Cultural, 2012 y las colecciones dirigidas por Renate Marsiske y Pablo Buchbinder. Marsiske, Renate (coord.): Movimientos estudiantiles en la historia de América Latina V, México D.F, Universidad Nacional Autónoma de México, 2017 y Buchbinder, Pablo (dir.): Juventudes Universitarias en América Latina: ayer y hoy, Rosario, Universidad Nacional de Rosario, 2019.

6 En su dimensión universitaria el movimiento de la Reforma se desencadenó tras la movilización estudiantil en la Universidad Nacional de Córdoba en junio 1918, lo cual derivó en la reforma de los estatutos de todas las universidades del país. Entre sus principales demandas se incluía la participación estudiantil en el gobierno universitario, la docencia y la asistencia libre, la autonomía universitaria, etc. En su faceta extrainstitucional la Reforma implicó el activismo de las juventudes en el campo político e intelectual del periodo. Entre la abundante bibliografía sobre esas dimensiones de estudio se incluye, junto con otras investigaciones citadas algunas a lo largo de este artículo, véase los trabajos de: Buchbinder, Pablo: ¿Revolución en los claustros? La Reforma universitaria de 1918, Editorial Sudamericana, Buenos Aires, 2008; Graciano, Osvaldo: Entre la torre de marfil y el compromiso político. Intelectuales de izquierda en la Argentina, 1918-1955, Bernal, Universidad Nacional de Quilmes, 2008.

7 Se sigue el concepto de Bourdieu sobre las representaciones sociales, las cuales actúan como "términos performativos que constituyen el sentido del mundo social tanto como lo registran, consignas que contribuyen a producir el orden social, informando el pensamiento de este mundo y produciendo así los grupos por ellas designados y movilizados". Bourdieu, Pierre: Las estrategias de la reproducción social, Buenos Aires, Siglo XXI, 2011, p. 187. Para abordar el modelo de sociabilidad de la ACJ remitimos a los aportes de Maurice Agulhon, del cual retomamos la dimensión de las formas institucionalizadas o asociativas de la sociabilidad, aunque ello no excluya lo intersocial cotidiano ni implique un enfoque dicotómico que oponga la sociabilidad formal e informal. Agulhon, Maurice: $E l$ Círculo Burgués. La sociabilidad en Francia, 1810-1848, Buenos Aires, Siglo XXI, 2009.

8 Al enfocarnos en el estudio de las asociaciones no se desconoce la amplitud del universo relacional de las juventudes dentro de campos más amplios. En ese sentido, la sociabilidad como categoría de análisis también ha sido señalada por Bourdieu como noción compleja que abarca el estudio de los modos de interacción cotidiana y las formas de agrupación permanente o modos de asociación, cuyos criterios de criterios de clasificación que exceden a los de la función declarada. Agulhon, Maurice: El círculo... p. 194, n. 34. 
a la población juvenil (provenientes de las escuelas y colegios secundarios, la universidad o del ejército) la convocatoria de la ACJ no se asentaba en la obligatoriedad sino en lazos voluntarios propios del asociacionismo; sus actividades no se orientaban unicamente hacia una proyección laboral o profesional o una obligación cívica-estatal sino al tiempo de ocio y el desarrollo de prácticas recreativas y su carácter confesional cristiano (si bien flexible) difería del principio laicista que se afirmaba, aunque con limitaciones, en los citados espacios institucionales. Finalmente, esta aproximación implica no solo tener en cuenta esos contrastres sino también otros que se establecían en relación a las mismas juventudes hacia quienes la asociación extendió su convocatoria. Tal como se analiza en el artículo, la difusión de representaciones y prácticas por las cuales la ACJ buscó modelar a un sujeto joven, desde una serie de comportamientos, valores y roles genéricos, se estableció en contraposición o en competencia directa con otras experiencias y formas de identidad que llevaban a cabo las juventudes porteñas.

\section{La difusión de un modelo: la Fundación de la Asociación Cristiana de Jóvenes en Argentina}

Según la historia institucional, la YMCA fue fundada en Londres en 1844 por George Williams, un joven empleado de una tienda comercial que ideó la asociación como un espacio de "diversión sana" para hacer frente al "horario inhumano", "las condiciones muy poco higiénicas" de trabajo y la "proximidad de la inevitable taberna". Frente a esos males la entidad surgió como un movimiento de propaganda a favor de la lectura del evangelio entre los jóvenes empleados, el cual rápidamente se expandió por fuera del ámbito inglés. ${ }^{9}$ Más allá de su origen británico la publicación distinguía que fue en Estados Unidos donde había adquirido su orientación definitiva, al incluirse allí, junto a los propósitos originales de "mejoramiento espiritual, intelectual y social de la juventud", una finalidad relativa al "mejoramiento físico", que ayudó a definir el programa cuatrifásico distintivo de la YMCA. ${ }^{10}$

Pese a que no se mencionaba en la citada reseña histórica, las preocupaciones por el "mejoramiento físico" también estaban presentes dentro de la comunidad protestante inglesa, a través del Muscular Christianity. A partir de la obra del ministro y novelista Charles Kinsley, y de otros propagandistas como Thomas Hughes, este movimiento contribuyó a la difusión de nuevos valores dentro del cristianismo evangélico, mediante los cuales los principios de piedad, compasión y de autocontrol de las pasiones, se combinaban con la afirmación de la virilidad, la fortaleza física, acercándose incluso a veces al culto a la fuerza. ${ }^{11} \mathrm{El}$ impacto de los principios del Muscular Christianity en la YMCA han sido señalado en diferentes investigaciones. ${ }^{12}$ De este modo, las inquietudes por las que surgió la entidad, no solamente se enmarcaban, como se mencionaba en la reseña, dentro los problemas sociales que

\footnotetext{
“Qué es la Asociación Cristiana de Jóvenes? I”, Boletín de la Y.M.C.A, 11-12 (1916), p. 1.

“Qué es la Asociación Cristiana de Jóvenes? II”, Boletín de la Y.M.C.A, 1 (1917), p. 2.

Mosse, George: The image of man. The creation of modern masculinity, New York, Oxford University Press, 1996, p. 49.

12 Lesko, Nancy: Act your age! A Cultural Construction of Adolescence, New York, Routledge, 2012. ( $1^{\mathrm{a}}$ ed. 2001), p. 47; Macleod, David: Building character in the American boy: The Boy Scouts, YMCA, and their forerunners, 1870-1920, Madison, University of Wisconsin Press, 1983, p. 45; Winter, Thomas: Making Men, Making Class: The YMCA and Workingmen, 1877-1920, Chicago, Chicago University Press, 2002, p. 5.
} 
implicaban los procesos de urbanización e industrialización sino también dentro de la definición de nuevos estereotipos e ideales sobre la hombría, que proponía ese movimiento, en respuesta al desarrollo del capitalismo y sus potenciales amenazas a las creencias religiosas, la estabilidad social y el sentimiento nacional. ${ }^{13}$

Estas inquietudes también estaban presentes en el contexto norteamericano, en donde la YMCA se integró, de forma pionera, dentro de una serie de organizaciones voluntarias orientadas a la población juvenil e infantil masculina (los Boys ' Clubs, el movimiento Big Brother y posteriormente los Woodcraft Indians, los Hijos de Daniel Boone y los Boy Scouts). ${ }^{14}$ A través de sus actividades deportivas y recreativas, según reconstruyen distintas investigaciones, estas entidades representaban una opción a los estratos medios de ese país para revitalizar su autoridad, unida a la afirmación de la ideología de la "supremacía blanca", y reformular las nociones de hombría frente a los desafíos que representaban para estos sectores el proceso inmigratorio, la organización del movimiento obrero, los reclamos de participación política de las mujeres, entre otros factores. ${ }^{15}$ Esas cuestiones también fueron centrales para la emergencia de las primeras conceptualizaciones científicas sobre la adolescencia, entre las caules la obra de Stanley Hall fue una de las principales influencias teóricas para el desarrollo de las citadas asociaciones juveniles. ${ }^{16}$

En relación al desarrollo de la YMCA, la creación de una burocracia fue crucial para la ampliación de esta entidad dentro y fuera del ámbito estadounidense. Dentro de ese país, la alianza con familias representantes de las elites industriales, como benefactoras financieras, permitió la expansión de la YMCA a través de la construcción de nuevos edificios, la formación de cuadros profesionales y la conformación de un entramado burocrático que conectara las distintas entidades. ${ }^{17}$ Más allá del contexto local, el desarrollo de dicha burocracia se expresó a través de la Comisión Internacional de Asociaciones Cristianas de Jóvenes de Norte América. La creación de la filial argentina en 1902, en paralelo a la fundación de sucursales en otras ciudades sudamericanas como Río de Janeiro y Montevideo, fue motivada por la asociación de Duluth (Minnesota) y formó parte de una estrategia que incluyó el envío de un secretario financiado por dicha entidad y de una cuantiosa donación proveniente de la Comisión Internacional para el establecimiento de un local propio. La difusión del modelo también convocó la alianza con empresarios ingleses radicados en Buenos Aires (varios gerentes de empresas tranviarias y ferroviarias y de otras compañías comerciales inglesas), quienes figuraron dentro del grupo fundador junto al cónsul británico, Carnegie Roos, y otros referentes religiosos y profesionales de la comunidad británica y norteamericana. ${ }^{18}$

Si bien el elenco británico resultó predominante en su etapa fundacional, la continuidad del modelo norteamericano estuvo asegurada por la efectiva dirección que

13 Sobre estas cuestiones véase: Hall, Donal: Muscular Christiany: Reading and Writing the male social body, en Donald E. Hall (ed.) Muscular Christianity. Embodying the Victorian age, New York, Cambridge University Press, 2006. (1 ${ }^{\mathrm{a}}$ ed. 1994), pp.8-10; Mosse, George: The Image of ... p. 49.

14 Jordan, Benjamin René: 'A Modest Manliness': The Boy Scouts of America and the Making of Modern Masculinity, 1910-1930, tesis doctoral, San Diego, University of California San Diego, 2009, pp. 72-73.

15 Bederman, Gail: Manliness and civilization: A cultural history of gender and race in the United States, 18801917, Chicago, University of Chicago Press, 1995, pp. 10-15; Winter, Thomas: Making Men...

16 Lesko, Nancy: Act your ...p. 26.

17 Winter, Thomas: Making Men...pp. 2-3.

18 ¿Qué es la Asociación Cristiana de Jóvenes? IV", Boletín de la Y.M.C.A, 5 (1917), p. 2. 
desempeñaron sucesivamente los secretarios de ese origen y la reproducción de una serie de programas y actividades sociales y deportivas ancladas en el formato de la YMCA americana y en referencias culturales estadounidenses. A su vez, la difusión de dicho modelo coincidía con el desarrollo del panamericanismo, impulsado por Estados Unidos en la búsqueda de nuevos mercados en la región, dominada hasta momento por capitales europeos. ${ }^{19} \mathrm{El}$ atractivo de la vocación social y cultural de la YMCA, dentro de la trama de proyectos político-económicos que promovía ese movimiento a escala continental, se hacía explícito a través de la propaganda que realizaba Leo Rowe, director de la Unión Panamericana en la década del veinte, al auspiciar las asociaciones cristianas como escuelas de ayuda mutua y de "sentimiento democrático", del que carecían, según su visión, los países americanos. ${ }^{20}$

Pese a la impronta del formato norteamericano, la difusión del modelo se pretendía asegurar mediante la adopción de un estilo nacional (a través de conferencias y actividades patrióticas) y de un "espíritu liberal", abierto a distintas religiones y tendencias políticas que confluyeran en el amplio reconocimiento de los principios éticos de la civilización cristiana. A su vez la asociación se promocionaba asegurando la autonomía y la "completa independencia" de cada uno de sus centros, a través de la financiación por medio de las membrecías locales y de las donaciones locales. ${ }^{21}$

Sin embargo, si bien la creación de sucursales sudamericanas confluía con los propósitos culturales del panamericanismo, tal como se advierte en el caso de la ACJ de Buenos Aires, la adopción de los propósitos de la entidad por parte de grupos intelectuales locales implicó la elaboración de otras propuestas e intereses que excedían las coordenadas de ese movimiento. En la segunda década del siglo XX, al lograr su consolidación organizativa, la participación de profesionales y figuras destacadas del campo científico-universitario de diversas filiaciones políticas y religiosas inscribió a la ACJ dentro de una trama más densa de asociaciones y de tendencias intelectuales que confluyeron en la elaboración de distintos tópicos y representaciones sobre las juventudes.

\section{La definición de una convocatoria y de un "campo juvenil" en la agenda pública}

La consolidación de la ACJ, materializada en la construcción de un local propio en 1912, coincidió con la extensión de su membresía más allá del grupo fundacional angloamericano y del elemento estudiantil univeresitario local, al que originalmente estuvo orientada. ${ }^{22} \mathrm{~A}$ su vez esa proyección hacia a la comunidad nacional coincidía con la renovación del órgano y de los medios de prensa de la asociación, a través de

19 Ortemberg, Pablo (dir.): Dossier: "Panamericanismo, hispanoamericanismo y nacionalismo en los festejos identitarios de américa latina, 1880-1920. Performances y encrucijadas de diplomáticos e intelectuales", Anuario IHES, 321 (2017), p. 100.

20 "El rol social de las Asociaciones Cristianas de Jóvenes. (Palabras pronunciadas en la A. de Santiago de Chile, por el Director de la Unión Panamericana Dr. Leo S. Rowe)", Boletín de la Asociación Cristiana de Jóvenes YMCA, 7 (1923), p. 1.

21 Asociación Cristiana de Jóvenes: Iniciativa Universitaria, Buenos Aires, Asociación Cristiana de Jóvenes, 1909 , p. 9.

22 El elemento predominantemente angloamericano del grupo original se hacía constar, como una tendencia superada en 1927, en el detalle de que el $67 \%$ de los socios fundadores eran británicos-norteamericanos y que, excepto unos pocos casos, el porcentaje restante era criollo, pero de origen anglosajón. Asociación Cristiana de Jóvenes: Veinte y cinco años...p. 43. A su vez la orientación universitaria fue promovida por una acción propa- 
la publicación de un boletín redactado en español y de los anuncios de sus actividades en reconocidos diarios y revistas de la ciudad. ${ }^{23}$

A partir de la segunda década del siglo, se buscó ampliar la masa societaria por medio de la creación de nuevas divisiones y la adopción de un perfil confesional abierto a distintas religiones. ${ }^{24}$ Sin embargo, más allá de esta apertura, la organización delimitó con claridad quiénes eran los jóvenes a los que convocaba a partir de una serie de categorias etáreas, sociales y genéricas que, si bien provenían del modelo norteamericano, se reelaboraban en el contexto local.

Desde un criterio etáreo, la contrucción de un público juvenil se desarrollaba por medio de secciones que articulaban esa categoría con una función social, identificada con el sistema educativo o con determinadas ocupaciones laborales. Así, la pertenencia a la división central se establecía en contraposición a la división universitaria y abarcaba a empleados, comerciantes y profesionales, mayores de 16 años. Posteriormente se agregaron instancias previas con la incorporación de las secciones cadetes (de 10 a 16 años) y secundarios (hasta los 18 años o el ingreso a la universidad).

Sin embargo, la correspondencia de este componente etario/socio-profesional con un reclutamiento de clase media, tal como se advierte para el caso estadounidense, no resulta tan clara en el caso argentino, en donde para este periodo se ha señalado la heterogeneidad de condiciones objetivas junto a la falta de solidaridad e identificación dentro de los estratos medios y la escasa circulación de esa denominación en la época. ${ }^{25}$ Esa heterogeneidad se observa también en relación al estudiantado de la universidad porteña, al que buscaba congregar la ACJ. Desde principios de siglo, la composición de dicha población, tradicionalmente identificada con las elites criollas, experimentaba un proceso de diversificación social mediante el crecimiento de la matrícula y el ingreso de estudiantes de procedencia inmigratoria o que representaban una primera generación en acceder a la universidad. ${ }^{26}$ A partir de ello, la falta de una identidad claramente definida en términos de clase puede apreciarse en la ACJ en el contraste entre ciertas apreciaciones que señalaban el interés que despertaba la asociación "particularmente en la clase alta" ${ }^{27}$ y otros indicadores, que enfatizaban en sus ventajas "económicas" 28 y en la condición de empleados de varios de sus asociados. Para 1922 las ocupaciones profesionales, empleos en diversos rubros o de

gandística dirigida a ese público, a cargo de una comisión compuesta por estudiantes y por un reconocido grupo de profesores e intelectuales. Asociación Cristiana de Jóvenes: Iniciativa Universitaria...p. 2.

23 Como antecesor a dicho boletín la asociación contó en sus inicios con una publicación, denominada Assosiation News, presumiblemente redactada en inglés. “¿Qué es la Asociación Cristiana de Jóvenes? IV”, Boletín de la Y.M.C.A, 5 (1917), p. 2. Por referencias internas y externas al boletín sabemos que las actividades de la ACJ eran difundidas en diarios y revistas locales como La Prensa y Caras y Caretas.

24 Se aceptaba como socio activo y dirigente "a cualquiera que se confiese discípulo de Cristo de cualquier escuela". "La asamblea anual del 18 de marzo", Boletín de la Asociación Cristiana de Jóvenes. Y.M.C.A, 4 (1919), p. 3. A su vez la apertura confesional se observa en las religiones de los socios. Para 1925 se registraba un total de "1298 católicos; 700 sin religión declarada; 483 protestantes; 283 cristianos no afiliados a ninguna denominación; 78 librepensadores; 64 israelitas, 4 ortodoxos y 7 de varias religiones". "La asamblea del 9 de marzo", Boletín de la Asociación Cristiana de Jóvenes. Y.M.C.A, 3-5 (1925), p.3.

25 Adamovsky, Ezequiel: Historia de la clase media en la Argentina. Apogeo y decadencia de una ilusión, Buenos Aires, Planeta, 2010. (1 ${ }^{\circ}$ ed. 2009).

26 Sobre ese proceso dentro de la universidad porteña véase: Carreño, Luciana: Los estudiantes universitarios en tiempos de reformas. Sociabilidad y vida estudiantil en la universidad porteña (1900-1930), Buenos Aires, Eudeba, 2020.

27 “La prensa' y nuestra casa", Boletín de la Asociación Cristiana de Jóvenes. Y.M.C.A, 2 (1919), p. 5.

28 Ello se observa a partir del sistema de membrecía de la ACJ, que incluía distintos tipos de socios con la posibilidad de optar por cuotas económicas. 
comercio integraban la sección de socios plenos más numerosa (2170 frente a 678 cadetes y 1043 estudiantes), que la asociación presentaba como mayoritariamente compuesta por jóvenes de menos de 30 años, aunque también admitía la presencia de personas de mayor edad. ${ }^{29}$ Por fuera del registro de socios plenos, el alcance más amplio que la asociación pretendía asegurar incluía otras actividades (como el uso de gimnasio o del "Restaurante Económico") que congregaban a "millares de jóvenes", según el discurso propagandístico de la institución. ${ }^{30}$

A su vez, y pese a las divisiones internas, esta convocatoria juvenil, que abarcaba simultáneamente a oficinistas y comerciantes junto a sectores universitarios cuya composición se tornaba a la vez más heterogénea, coincidía con una pérdida de referencia que experimentaban las elites sociales. Según ha señalado Losada para el periodo de entreguerras, las posibilidades de estos grupos de edificar una distinción social y cultural no solo se veían afectadas por la crítica moral que pesaba sobre las conductas modernas y licenciosas de las juventudes de esos sectores, sino también por la homogenización cultural que provocaba el capitalismo y la generalización de modas provenientes de otros sectores sociales, como el jazz o el tango. ${ }^{31}$ Lejos de buscar pautas de consumo diferenciadas, la ACJ incorporó estas novedades culturales, a través de su orquesta de jazz y sus funciones de one step, fox trots, tangos y shymmis, cuyos posibles desvíos licenciosos se depuraban en el ambiente familiar de la asociación. En ese mismo sentido, la entidad contribuyó en la difusión de pasatiempos, por medio de los clubes de fotografía, filatelia, billares y radio, ${ }^{32}$ que contribuían a encauzar y difundir nuevas prácticas de ocio juvenil y a fomentar los fines de "sociabilidad" en vinculación con la obra de "mejoramiento general de la sociedad" a la que aspiraba la asociación. ${ }^{33}$

La construcción de un público juvenil se realizó también mediante una interpelación basada en concepciones y roles genéricos. En paralelo al desarrollo de otras prácticas de la cultura física que se difundieron en las primeras décadas del siglo (como el scauting o la gimnasia militar) y de la implementación del servicio militar obligatorio (sobre el cual se ha demostrado que su pretendido consenso entre la

"Memoria del Director- Secretario (interino) de la ACJ, correspondiente al año 1921. Boletín de la Asociación Cristiana de Jóvenes. YMCA, 1-4 (1922), p. 1.

30 Según dicho discurso propagandístico, que como tal resulta importante poner en cuestión, a lo largo de 1919 se afirmaba un total de 160.000 concurrentes al gimnasio y que las comidas servidas en el comedor económico ascendían a 90.685. Asociación Cristiana de Jóvenes: $18^{\circ}$ informe anual ...p. 5.

31 Losada, Leandro: "Convenciones culturales y estilos de vida. La elite social de la Argentina de entreguerras en las crónicas sociales de la revista Caras y Caretas (1917-1939)", Social and Education History, 2 (2013), pp. 170-171.

32 "Clubes internos", Boletín de la Asociación Cristiana de Jóvenes. Y.M.C.A, 5-6 (1923), p. 4.

33 Retomamos el planteo de González Bernaldo de considerar el marco conceptual e ideológico vinculado al concepto de sociabilidad. Según la autora, en el Río de la Plata posindependiente, la "sociabilidad" remitía a dos acepciones diferentes (remitía una a la idea de civilidad como virtud privada y otra a la idea de asociación como virtud de moral pública) pero imbricadas entre sí, en tanto la civilidad, como código relacional vinculado a la conversación y al trato amable, contribuía a definir las relaciones en la esfera pública y ésta a pensar la sociedad civil. González-Bernaldo de Quirós, Pilar: "La 'sociabilidad' y la historia política", Nuevo Mundo Mundos Nuevos, (7). Esta relación entre las formas de cultivar el trato social y de pensar e intervenir en la vida pública, se interpretan en relación a los fines de "sociabilidad" que auspiciaba la ACJ, mediante los citados clubes de aficionados, la realización de conciertos y reuniones sociales. Sin embargo, tanto esos fines como otros eminentemente intelectuales o deportivos, "lejos de circunscribir su acción a la esfera siempre limitada de los miembros que la componen" buscaban "influir benéficamente en todas las esferas sociales". Asociación Cristiana de Jóvenes: Iniciativa Universitaria...p. 10 
población distaba de constituir una instancia libre de oposiciones) $)^{34}$ el modelo de la ACJ se orientó a la constitución masculina de los cuerpos juveniles mediante el desarrollo de los ejercicios "científicos" y calisténicos al aire libre y la realización de los campamentos anuales. Al igual que ha señalado Scharagrodsky para el scautismo en su difusión por Argentina, la configuración de determinadas masculinidades se realizaba simultáneamente a través de una cierta disposición corporal entendida como correcta y de una serie de valores que confluían a ese fin..$^{35}$ En el caso de los jóvenes cristianos, esos valores se identificaban con los del Muscular Christianity y de los deportes ingleses (disciplina, autocontrol, caballerosidad, juego limpio, amateurismo, etc.). Pero a diferencia de las masculinidades promovidas por la cultura física o el servicio militar, el modelo de la ACJ se distinguió por difundir los deportes grupales (entre los cuales el básquet fue su sello distintivo), individuales (natación, atletismo, gimnasia de aparatos, etc. $)^{36} \mathrm{e}$ inclusive, de origen popular, como el boxeo y la lucha, que no se asociaban en la época con los citados valores. Pese a ello, en la propaganda que se hacía de que "Aquí el cristianismo muscular desarrolla sus energías en las actividades eminentemente cristianas del boxeo y la lucha", los atractivos esos deportes en el desarrollo de la virilidad se aprovechaban para reformularse completamente. ${ }^{37}$

La contención de los jóvenes a través del ocio y la construcción de cuerpos sanos y varoniles por medio del deporte se combinaban con aquellas actividades que buscaban asegurar su correcta descendencia por medio de la educación sexual. Las distintas iniciativas al respecto, vincularon a la ACJ con una heterogénea red de intelectuales que, en torno a la profilaxis de las enfermedades venéreas, reunía a representantes del partido socialista, del incipiente movimiento eugenésico y de otras entidades intelectuales reformistas, como el Museo Social. ${ }^{38}$ En relación al socialismo, dentro de los colaboradores estables se destacó Ángel Giménez, principal animador

34 Estudios recientes han reconstruido distintas formas de oposición a la conscripción, que provenían tanto de las críticas y acciones antimilitaristas de diferentes sectores de la izquierda como de las variadas prácticas de los jóvenes para evitar o regresar anticipadamente del servicio militar. Ablard, Jonathan: "The Barracks receives spoiler children and returns men": Debating Military Service, Masculinity and Nation-Building in Argentina, 1901-1930". The Americas, 743 (2017), pp. 1-31; Silliti, Nicolás: "El Servicio Militar Obligatorio y la "cuestión social”: apuntes para la construcción de un problema historiográfico". Pasado Abierto, 7 (2018), pp. 265-275.

35 Scharagrodsky, Pablo: "El scautismo en la educación física bonaerense o acerca del buen encauzamiento varonil (1914-1916)", en Ángela Aisenstein y Pablo Scharagrodsky (dirs.): Tras las huellas de la educación física escolar argentina. Cuerpo, género y pedagogía. 1880-1950, Buenos Aires, Prometeo, 2006, pp. 155. La ACJ contribuyó al desarrollo del scautismo en Argentina, al patrocinar la visita del fundador de ese movimiento, Robert Banden Powell, en 1911. Asociación Cristiana de Jóvenes: Veinte y cinco años de acción en la Metrópoli Argentina. 1902-1927, Buenos Aires, Asociación Cristiana de Jóvenes, 1927, p. 35.

36 Bajo el liderazgo de Luther Gulick, en la filial de Springfield, los deportes competitivos remplazaron a la gimnasia en los programas de la YMCA. En relación a los deportes grupales ello dio lugar a la invención del básquet en 1891 por James Naismith en esa sucursal. Grundy, Pamela y Rader, Benjamin: American Sports. From the Age of Folk Games to the Age of Televised Sport, New York, Routledge, 2016. (1 ${ }^{\mathrm{a}}$ ed. 2004), p. 113.

37 "La asamblea anual del 18 de marzo", Boletín de la Asociación Cristiana de Jóvenes. Y.M.C.A, 4 (1919), p. 3. Según Bederman, la adopción del boxeo y la lucha por parte de la YMCA se incluía dentro de las estrategias de los sectores medios y altos estadounidenses de reformular sus nociones de hombría a través de las diferencias de clase y de la apropiación de los rústicos códigos de virilidad de la clase trabajadora, formulados en su origen en resistencia a las pautas moralistas y respetables de la noción de hombría victoriana. Bederman, Gail, Manliness...p. 17.

38 El Museo Social, creado en 1911, se constituyó como un reconocido centro de estudios sobre diferentes problemas económicos, sociales y políticos del país. La vinculación con la ACJ se dio a través de Ernesto Nelson, miembro de ambas asociaciones. Al ocupar la dirección del departamento de acción social en la ACJ en 1917, Nelson era un destacado educador, formado en Estados Unidos y promotor de la filosofía educacional de John 
de la Sociedad Luz. En periodo de entreguerras, esta entidad de educación popular del socialismo se distinguió, junto con otras asociaciones como la Liga Argentina de Profilaxis Social, por desarrollar acciones a favor de educación sexual; promover su inclusión dentro del sistema educativo y efectuar una demanda de legislación estatal. ${ }^{39}$ A su vez, Raúl Ortega Belgrano, otro de los principales conferencistas en esta materia se relacionó, junto con Giménez, con la creación del fallido Instituto Pro- adolescencia de Investigaciones sobre la Educación Sexual, una de las primeras iniciativas del movimiento eugenésico que se definía en sintonía a las tendencias liberales europeas y norteamericanas sobre la cuestión sexual. ${ }^{40}$

Dentro de la ACJ la circulación de estas tendencias se advierte en la campaña a favor del libro de Hans Wegener, Nosotros los jóvenes. El problema sexual del joven soltero, traducido del alemán por el pedagogo español Luis de Zulueta. ${ }^{41}$ En ese libro, la juventud era representada como una etapa atravesada por el instinto sexual, el cual era entendido como una fuerza "creadora" que daba "al alma el poder de sentir virilmente". ${ }^{42}$ Desde una legitimación que se afirmaba en la naturaleza, el instinto actuaba como uno de los factores en los se construía la diferencia sexual, estableciéndose para hombres y mujeres distintos modos de transitar ese pasaje entre la adolescencia y la juventud. Al considerarse "indudable que el hombre está en mucho mayor peligro de contaminar su pureza, a causa (...) de su estructura física", ${ }^{43}$ se afirmaba que eran los jóvenes solteros a quienes más había que precaver y respecto a quienes podían resultar entendibles posibles "desvíos", siempre entendidos desde la norma heterosexual (la prostitución, las queridas o la masturbación).

Estas nociones, que se promovían a través de charlas, lecturas entre padres e hijos y la constitución de un "círculo de educación sexual" entre los estudiantes secundarios, se ajustaban a las que difundían las mencionadas conferencias sobre profilaxis, las cuales, según plantea Queirolo, si bien se proponían combatir las enfermedades venéreas, terminaban reforzando de manera simbólica el sistema de género binario y la sexualidad reproductiva. ${ }^{44}$ A partir de esa trama, que combinaba la circulación internacional de saberes sobre la cuestión sexual, las acciones provenientes de la sociedad civil y aquellas que comenzaban a integrarse dentro del sistema educativo, ${ }^{45}$ la figura del joven adquiría una mayor densidad, delimitando un segmento entre la pubertad y la edad de matrimonio como problema diferenciado dentro de la agenda pública. Ello se daba en paralelo y como complemento de la emergencia de la problematización de la categoría de la adolescencia dentro del sistema educativo local, tal como observa en la publicación, en 1918, de la obra del pedagogo Víctor Mer-

Dewey en Argentina. Becerra Solá, Malena: El museo Social Argentino (1910-1930). Cuestión social y redes internacionales de reforma, tesis doctoral, Madrid, Universidad Autónoma de Madrid, 2015.

39 Queirolo, Graciela: "Género y sexualidad en tiempos de males venéreos (Buenos Aires, 1920-1940)", Revista Nomadias, 17 (2013), pp. 67-87.

40 Vallejo, Gustavo: "La hora cero de la eugenesia en la Argentina: disputas e ideologías en el surgimiento de un campo científico, 1916-1932”, História, Ciências, Saúde Manguinhos, 25 (2018), pp. 19-20.

41 Wegener, Hans: Nosotros los jóvenes. El problema sexual del joven soltero, Madrid, Daniel Jorro Editor, 1910. $\left(1^{\mathrm{a}}\right.$ ed. 1906).

42 Wegener, Hans: Nosotros...p. 15.

43 Wegener, Hans: Nosotros...p. 90.

44 Queirolo, Graciela: "Género...p. 83.

45 Sobre la introducción de la educación sexual en la escuela pública véase: Lionetti, Lucía: "Discursos, representaciones y prácticas educativas sobre el cuerpo de los escolares. Argentina en las primeras décadas del siglo XX", Cuadernos de Historia, 34 (2011), pp. 31-52. 
cante La crisis de la pubertad y sus consecuencias pedagógicas. Según ha analizado Dussel, aunque la adolescencia como categoría resultaba aun poco conocida entre buena parte de la sociedad, la ampliación de la escolaridad secundaria, pese a ser aún minoritaria, comenzó a evidenciar cuestiones sobre esa población escolar que hasta ese momento no habían ocupado lugar en el espacio público. ${ }^{46}$

Finalmente, la convocatoria juvenil delimitada en roles genéricos se completaba a través de las actividades de la Asociación Cristiana Femenina (ACF), que, aunque era una entidad organizativamente independiente, se vinculaba estrechamente con la ACJ. La ACF contribuyó a la difusión de los deportes grupales para mujeres, los cuales, si bien tenían su equivalente masculino, respetaban los principios de la diferencia sexual a través de reglamentaciones que distinguían completamente los distintos deportes. ${ }^{47}$ Según estudios sobre esa asociación en Buenos Aires, si bien la práctica del deporte femenino era acompañada por nociones maternalistas y eugenésicas comunes en la época, la innovación en la socialización de deportes, como el tenis, el vóley o el básquet, junto a otras actividades sociales contribuían a promover la influencia de las mujeres por fuera de la esfera doméstica. ${ }^{48}$ Dentro de la ACJ, la participación de las mujeres se registra en funciones relativas a la organización de fiestas sociales, patrióticas y de eventos como la "Semana de la oración", la "Semana del nene" y del día de la madre, festividad que fue introducida por la asociación siguiendo el ejemplo estadounidense. Sin embargo, la afirmación del rol maternal y piadoso de las mujeres, que se advierte en dichas actividades, convivía con otras iniciativas que vincularon a la asociación con intelectuales feministas, a la vez que se fomentaba el acceso de las mujeres a la educación superior. ${ }^{49}$

Pese a estas delimitaciones genéricas y sociales en las cuales se encuadraba la definición de un público juvenil, los objetivos de la asociación implicaron una concepción mucho más extensiva sobre este sector y sobre los alcances a los que aspiraba la convocatoria:

Su campo de acción es la juventud, "tesoro divino", que dijera el poeta, la juventud, en cuyo seno se gesta el porvenir ¡Campo inmenso el que ella ofrece, que llama a trabajarlo con amor, a millares de obreros! ¡Campo que sin embargo en tantos sentidos descuidado y que se haya constituido en Buenos Aires por 371.181 jóvenes entre los diez y siete y 30 años, de los cuales apenas esta asociación alcanza a irradiar su influencia sobre un 1 por $100 !^{50}$

46 Dussel Inés: "Víctor Mercante: La adolescencia como categoría escolar. La emergencia de una problematización" en Víctor Mercante: La crisis de la pubertad y sus consecuencias pedagógicas, La Plata, UNIPE-Editorial Universitaria, 2014, p. 12.

47 Grundy, Pamela y Rader, Benjamin: American Sports...pp. 92-95.

48 Anderson, Patricia: "Deporte y civismo femenino en la Asociación Cristiana Femenina de Buenos Aires, 1890 1940", en Pablo Scharagrodsky (coord.): Mujeres en movimiento: deporte, cultura fisica y femineidades, Argentina, 1870-1980, Buenos Aires, Prometeo, 2016, p. 196.

49 Se citan, entre otras, las conferencias de la militante del feminismo socialista, Alicia Moreau, sobre "El feminismo como problema social". "Las conferencias dominicales de junio", Boletín de la Asociación Cristiana de Jóvenes. Y.M.C.A, 7 (1919), p. 2 y sobre "La Mujer obrera" "Las Reuniones dominicales de julio y agosto", Boletín de la Asociación Cristiana de Jóvenes Y.M.C.A, 8-9 (1920), p. 5. Asimismo, la obra de la ACJ respecto a la educación de las mujeres fue auspiciada en el Primer Congreso Femenino Internacional celebrado en Buenos Aires en 1910

50 "La Asociación Cristiana de Jóvenes. Fijando conceptos", Boletín de la Asociación Cristiana de Jóvenes. Y.M.C.A, 10 (1920), p. 1. 
Al definirla como un campo de acción, la juventud aparecía, o se pretendía instalar, como un objeto de consideración dentro de la agenda pública. En esa tarea la asociación se legitimaba al incursionar pioneramente en este ámbito (dado que se afirmaba como "descuidado") y al tratar de difundir sus propias categorías etéreas en la configuración de dicho campo juvenil. Para lo cual, en la década del veinte la ACJ apostó por distintas estrategias de intervención pública por las que trataría de extender su alcance por fuera del sistema de membrecías que establecía su dispositivo asociativo.

\section{Modalidades de intervención pública de las juventudes cristianas.}

La atención que recibía el campo juvenil contrastaba con la recepción de otras iniciativas que convocaban un público infantil o en edad escolar obligatoria. Al finalizar la década del veinte el reclutamiento de la ACJ arrojaba un total de 4791 asociados $^{51}$ que contrastaban con los casi veinte mil miembros que aseguraba tener los Boys Scouts Argentinos en ese mismo periodo. ${ }^{52}$ A diferencia del escultismo la asociación tampoco contaba, en ese entonces, con filiales en otras ciudades del país ni con el patrocinio estatal de sus actividades dentro y fuera del sistema educativo. ${ }^{53}$ Pese a ello, la proyección social que la ACJ desarrolló en la década del veinte no solo da cuenta de la extensión de su convocatoria por fuera de la membrecía formal sino también de que, lejos de ser un campo de vacancia, las juventudes comenzaban a constituirse como agentes que llevaban a cabo específicas formas de intervención política y sus propias experiencias culturales.

A partir de su vinculación con el campo intelectual y universitario, la proyección social a la que apuntó la ACJ no solo aspiraba a la formación de jóvenes cristianos como "padres del porvenir", sino también a fomentar un rol científico y cultural en el desarrollo de liderazgos estudiantiles:

La sociedad contemporánea tiene apremiantes y graves problemas que resolver. La solución acertada de los mismos no procederá sino de aquellos que por la investigación científica hayan descubierto las causas directas e indirectas que los provocan. De las filas estudiantiles deben reclutarse estos investigadores modernos. Por lo tanto, hay que estimular el estudio de los mismos vinculando a los estudiantes con obras altruistas y filantrópicas. ${ }^{54}$

Esta represetanción coincidía con el papel de "futuras clases dirigentes" que se les asignaba a las juventudes desde la universidad, por el cual se apelaba a las res-

51 "La XXVa Asamblea Anual", Boletín de la Asociación Cristiana de Jóvenes. Y.M.C.A, 1 (1928), p. 4.

52 Bisso, Andrés: "Las conmemoraciones del "Día" y la "Semana del Scout" en Argentina (1928-1941)", en María Paula Bontempo y Andrés Bisso (eds.): Infancias y juventudes en el siglo XX: política, instituciones estatales y sociabilidades, Buenos Aires, Teseo Press, 2019, p. 119.

53 El patrocinio estatal del scautismo se concretó a través de un decreto presidencial, emitido en 1917, por el cual se creó el Instituto Nacional del Scoutismo Argentino. Para 1928 la difusión del scautismo por fuera del ámbito de la ciudad de Buenos Aires se aseguraba a través de sus ciento cincuenta compañías diseminadas por todo el país. Bisso, Andrés: "Las conmemoraciones...pp. 119-122. Por el contrario, en la década del veinte la ACJ no contó con una medida análoga que institucionalizara el reconocimiento estatal, aunque sus actividades eran auspiciadas a través de la presencia del Ministro de Educación, Antonio Sagarna, en varios actos de la entidad.

54 Asociación Cristiana de Jóvenes: $18^{\circ}$ informe anual... p. 19. 
ponsabilidades que les cabían a la población estudiantil frente la cuestión social y los desafíos que planteaba la apertura democrática. Al tratarse de una proyección a futuro, ese papel estaba supeditado a la función tutular y preparatoria que cumplía la universidad, que recibía al "joven para formarlo" y lo devolvía a la sociedad "transformado en hombre" ${ }^{55}$ Por el contrario, a partir del movimiento de la Reforma, las juventudes buscaron reformular esa misión directriz desde nuevas coordenadas ideológicas a partir de la Gran Guerra y la Revolución rusa. ${ }^{56}$ Para lo cual no solo rechazaron la función tutelar que les asignaba el sistema educativo, sino que también adoptaron un compromiso de acción mediante la participación en el gobierno universitario y el desarrollo de distintas modalidades de intervención pública (creación de revistas, formación de agrupaciones, extensión universitaria, etc.).

En ese contexto, las iniciativas de "acción social" que promovió la ACJ convocaban la participación estudiantil en un variado arco de problemas sociales a través del dictado de clases en la "Universidad Nocturna" ${ }^{57}$ o de conferencias a cargo de intelectuales, entre quienes que se incluyeron también referentes del movimiento reformista. ${ }^{58}$ Otras actividades integraban la dimensión profesional propia de la formación de los estudiantes que tomaban parte, con lo cual la proyección social que planteaba la ACJ pretendía contrarrestar al marcado "utilitarismo" que se acusaba en la universidad y que la propaganda de la Reforma contribuía a visibilizar en esos años. ${ }^{59}$ Sin embargo, si la ACJ podía coincidir con las juventudes reformistas en la identificación de distintos problemas sociales (trata de blancas, tuberculosis, condiciones laborales de las mujeres, etc.), el acuerdo sobre las finalidades de esa intervención resultaba más limitado en el marco de radicalización que experimentaba ese movimiento. Al proponer contener la "ola roja" con "la ola blanca del cristianismo" la asociación pretendía orientar la participación de los jóvenes hacia un programa encaminado a la "armonía social" ${ }^{60}$ que contrastaba con las propuestas de algunas agrupaciones juveniles que buscaban renovar la agenda reformista desde una impronta revolucionaria. ${ }^{61}$

55 Cantón, Eliseo: "La colación de grados en la Facultad de Ciencias Médicas", en Revista de la Universidad de Buenos Aires, XVII (1912), pp. 445-446.

56 Entre otras, una de principales obras que retomaron e inspiraron a las juventudes para ese fin fue el ensayo Ariel del escritor uruguayo José Enrique Rodó. Sobre la coyuntura y las referencias intelectuales e ideológicas del reformismo, en las que se dio la circulación y apropiación el mensaje arielista véanse entre otros trabajos: Biagini, Hugo: La contracultura juvenil...; Bustelo, Natalia: La reforma universitaria desde sus grupos y revistas. Una reconstrucción de los proyectos y las disputas del movimiento estudiantil porteño de las primeras décadas del siglo XX (1914-1928), Tesis doctoral, La Plata, Universidad Nacional de La Plata, 2015.

57 En 1916 se llevaron a cabo los cursos de la "Universidad Nocturna" a cargo de estudiantes, destinados "a todas las clases sociales". "Acción social", Boletín de la Y.M.C.A, 5 (1916), p. 3.

58 En la década del veinte se cita la participación de Alfredo Palacios y Florentino Sanguinetti, dos reconocidos referentes del reformismo. Sin embargo, esas conferencias convivieron con otras, como la que desarrolló el profesor universitario Alfredo Colmo, que sostenían posicionamientos críticos al desarrollo y politización del reformismo.

59 Ello se observa en los temas del club de debate en el que se discutía sobre la contribución o no de los abogados y médicos al bienestar social. "Club literario y de debates Sarmiento", Boletín de la Asociación Cristiana de Jóvenes. Y.M.C.A, 7 (1919), p. 3.

60 "Reuniones dominicales de septiembre", Boletín de la Asociación Cristiana de Jóvenes. Y.M.C.A, 10 (1919), p. 3 .

${ }_{61}$ Bustelo, Natalia y Domínguez Rubio, Lucas: "Radicalizar la Reforma Universitaria. La fracción revolucionaria del movimiento estudiantil argentino, 1918-1922", Anuario Colombiano de Historia Social y de la Cultura, 2 (2017), pp. 31-62. 
Asimismo, al tratarse de una asociación destinada pero no organizada por jóvenes, la proyección de la ACJ no terminaba de diferenciarse de las concepciones tutelares que circulaban en la universidad en relación a las juventudes. Por el contrario, si bien las prácticas de intervención pública que adoptaban las juventudes reformistas no resultaban una invención original, en tanto que remitían a formas de sociabilidad preexistentes en el campo intelectual, su apropiación en paralelo a la relaboración del tópico juvenilista en los años veinte dio lugar a nuevas formas de identificación. Especialmente, ello se expresó a través de la edición de revistas que pasaron a constituirse en un campo de experiencia juvenil, tensionado por interpelaciones diversas que provenían de los mismos agentes que se identificaban como jóvenes. ${ }^{62}$

Paralelamente, la proyección social de la ACJ estuvo acompañada por una "obra del barrio" mediante la inauguración de instalaciones en distritos, como San Telmo y Cafferata, que representaban distintas problemáticas de la expansión urbana. Este tipo de prácticas constituía una versión cristiana y deportiva de la extensión universitaria, en las cuales se buscaba expandir el ideal civilizatorio de la educación popular por fuera de las funciones meramente prescriptivas e informativas de las conferencias y contribuir con ello a otras finalidades. Por un lado, apuntaban al fortalecimiento de los liderazgos juveniles que llevaban adelante la acción en los barrios. Para ello, el departamento de educación física formaba sus propios cuadros técnicos, que cubrían específicas tareas dentro de las modalidades de intervención pública de la asociación: cooperar con las obras del barrio y de educación popular; dirigir clases de gimnasia en instituciones externas que lo solicitasen; participar en campeonatos deportivos, etc. ${ }^{63}$ Junto con este Cuerpo de Leaders se patrocinaban actividades acordadas específicamente para la división de cadetes (reparto de víveres a "familias pobres"), secundarios (obra en favor de los "canillitas") ${ }^{64}$ y universitarios (participación en la obra del barrio y en la Casa del Niño).

Por otro lado, estas prácticas promovían la difusión de hábitos higiénicos y la normalización de las conductas entre las clases populares. Para ello si bien la acción en el barrio apuntó a los jóvenes, a los que se buscaba alejar "del café y el cabaret" mediante la extensión de las actividades de la sede central (deportes grupales, pasatiempos, lecturas) o la ayuda en la obtención de un empleo, ${ }^{65}$ el principal objetivo se orientó a la "conquista del muchacho". ${ }^{66}$ En el diagnóstico de la asociación el "pibe de barrio", cuya afición al deporte no era nula, pero si limitada al fútbol como único interés, condensaba una serie de rasgos ("falta de orden y disciplina", "excesos de lenguaje", "brusquedad del carácter", "insubordinación contra el árbitro", "intole-

62 Ejemplos sobre interpelaciones juveniles diversas en torno a la edición de revistas puede verse en: Bustelo, Natalia: La reforma universitaria...; Carreño, Luciana: Los estudiantes...pp. 301- 324 y Cremonte, Martín: El momento sorelieano. Vitalismo, juvenilismo y fascismo en la revista Inicial (1923-1927), Tesis de maestría, Universidad Nacional de San Martín, Buenos Aires, 2018.

63 "Reglamento del cuerpo de leaders", Boletín de la Asociación Cristiana de Jóvenes. Y.M.C.A, 6-7 (1926), p. 2.

${ }^{64}$ En Argentina y otros países latinoamericanos la denominación "canillitas" refería a la ocupación de venta callejera de periódicos, generalmente asociada a personas de corta edad. "En favor de los canillitas", Boletín de la Asociación Cristiana de Jóvenes. Y.M.C.A, 6-7 (1925), p. 4.

${ }_{65}$ Segado, Ascencio: "La obra del barrio", Boletín de la Asociación Cristiana de Jóvenes, Y.M.C.A, 7 (1925), pp. 6-7.

66 Segado, Ascencio: "La conquista del muchacho", Boletín de la Asociación Cristiana de Jóvenes. Y.M.C.A, 2 (1928), p. 1. 
rancia para con el compañero más débil”) ${ }^{67}$ que lo definían como el contra estereotipo del joven cristiano.

Tal como se desprende de los estudios sobre el futbol, esos componentes se ajustaban a aquellos que caracterizaron la apropiación de esa práctica por parte de los jóvenes de los sectores populares. Según Frydenberg en ese proceso, valores como el exitismo, la búsqueda de visibilidad se combinaron con otros, como la honorabilidad y "la guapeza", que provenían de los códigos del barrio, el "arrabal" y los patios de los conventillos. En el contexto del masivo proceso de inmigración europea desarrollado en Argentina, la adopción del futbol en las primeras décadas del siglo XX implicó por parte de las juventudes la definición de un "estilo cultural generacional", por el cual marcaban una distancia de la familia, de la cultura inmigrante, de la élite local o de las directivas de la escuela pública. ${ }^{68} \mathrm{~A}$ su vez Archetti alude a esta adopción como una "hibridación" que resultaba trasgresora de las virtudes (como la belleza, el trabajo en equipo, la disciplina, etc.), que eran propias del estereotipo moderno de masculinidad asociado al futbol y a otros deportes europeos, ${ }^{69}$ que se difundían en la ACJ.

A partir de ello, no resulta sorprendente que, en el contexto de la "obra del barrio", las virtudes de los "híbridos masculinos" locales resistieran explícitamente aquellos valores y prácticas a los que recurría la ACJ para configurar las masculinidades juveniles. Allí la "conquista del muchacho" implicaba despertar el interés del "pibe de barrio" quien:

Intelectualmente (...) no sentía inclinaciones más que por alguna crónica de football (...) los libros de aventuras, los cuentos o las novelas de Verne o Salgari le aburrían por completo. Físicamente, las actividades presentadas por nuestra Asociación, según él, eran actividades para señoritas. ${ }^{70}$

Pese a ello, y a que incluso algunos intelectuales pertenecientes a la ACJ comenzaban a ver en ese proceso de apropiación original del futbol una metáfora que alentaba a adoptar posiciones proactivas frente los expansionismos culturales en la región, ${ }^{71}$ la estrategia en la obra del barrio se orientó en definitiva a lograr la extensión un programa referenciado en valores contrarios a los "híbridos" locales. Para lo cual, actividades propias de la asociación como el día de la madre, las clases y exhibiciones gimnásticas, los deportes grupales, etc. tenían su correlato en la obra del barrio. Con ello, al divulgar prácticas y valores propios de la cultura física (el juego limpio, la caballerosidad entre rivales, la disciplina, etc.) la propuesta de la ACJ contrastaba con otros modelos de sociabilidad juvenil, como el que llevaba a cabo el Club Universitario de Buenos Aires, que realizaban una apropiación distintiva y más

67 Asociación Cristiana de Jóvenes: Veinte y cinco...p. 25.

68 Frydenberg, Julio: Historia social del futbol: del amateurismo a la profesionalización, Buenos Aires, Siglo XXI, 2011, pp. 83- 89.

69 Archetti, Eduardo: Masculinidades: futbol, tango y polo en la Argentina, Buenos Aires, Deldragón, 2016, (1 ${ }^{\mathrm{a}}$ ed. 1999), pp. 117-118.

70 Segado: Ascencio: "La conquista...p. 14.

71 Vallejo, Gustavo: "El hombre nuevo: representaciones culturales en torno a la masculinidad en la Argentina (1918-1976)", Cuadernos de Historia Contemporánea, 40 (2018), pp. 95-96. Esta interpretación, que analiza Vallejo, corresponde al periodista y filósofo José Gabriel, quien también se destacó como un activo socio de la ACJ. 
exclusiva de dichos valores. ${ }^{72}$ Sin embargo, lejos de implicar un sesgo igualitario esa divulgación por parte de la ACJ se efectuaba bajo el liderazgo de los grupos que conducían la asociación y bajo pautas culturales que resultaban ajenas y resistidas en la esfera barrial. Así, si bien siempre se destacaba los resultados positivos a raíz del trabajo de persuasión y convencimiento, también se mencionaba que las instalaciones sufrían destrucciones y que sus cuidadores habían recibido agresiones físicas por parte de las juventudes del barrio.

Finalmente, la proyección social que desplegó la ACJ también incluyó a la población inmigrante como objeto de la convocatoria juvenil. Las aprensiones en esta materia constituían uno de los puntos de convergencia entre la filial argentina y las estadounidenses, dada la relevancia de los procesos inmigratorios en ambos países. Sin embargo, aunque comparativamente Estados Unidos recibió un número superior de inmigración ultramarina, en Argentina su proporción en relación a la estructura socio demográfica resultaba mucho mayor dado el menor tamaño de la población local. ${ }^{73}$ Frente a los desafíos que supuso ese proceso a la construcción de la nacionalidad en ese último país, la escuela pública y la invención de prácticas y símbolos patrios actuaron como instrumentos decisivos. ${ }^{74}$ En ese marco, además del señalado énfasis en el "estilo nacional", a través de fiestas y actos patrióticos, la ACJ orientó sus actividades hacia quienes arribaban entonces al país. Los citados cursos de la Universidad Nocturna, a cargo de estudiantes universitarios, se dirigían también a formación de la ciudadanía, al buscar interesar al "elemento extranjero" en el estudio de historia, geografía y el idioma nacional. ${ }^{75}$

Junto con la cuestión nacional, las acciones "en pro de los futuros padres de argentinos" 76 resultaban asimismo relevantes a partir de las mencionadas preocupaciones eugenésicas y del desequilibrio que el aporte inmigratorio había generado con el ingreso de más hombres que mujeres de las edades de 20 a 30 años. ${ }^{77}$ Para ese fin, en los años veinte la ACJ implementó una "Sección de inmigrantes" que tenía entre sus principales funciones la ayuda en la búsqueda de empleos, junto con otras tareas relativas a la radicación en el país (traducción gratuita de documentos, asistencia en la búsqueda de vivienda, etc.). Junto con las ayudas materiales, a través de los consejos, conversaciones, las visitas a hospitales y cárceles, la "obra entre inmigrantes" revestía una dimensión moral sobre las conductas y costumbres de quienes llegaban al país. De este modo, al igual que ocurría entre los jóvenes cristianos y los jóvenes y pibes del barrio, la juventud aparecía representada también entre los inmigrantes como una antesala de la paternidad y como objeto de la convocatoria de la ACJ.

72 En el sentido que remite a la obra Bourdieu sobre la distinción y su análisis de los consumo, gustos y estilos de vida que expresan determinados habitus y posiciones de distintos grupos sociales. Bourdieu, Pierre: La distinción. Criterios y bases sociales del gusto, Madrid, Taurus, 1998, (1 ${ }^{\mathrm{a}}$ ed. 1979). Sobre el modelo de sociabilidad del Club Universitarios de Buenos Aires véase: Carreño, Luciana: Los estudiantes...pp. 335-344.

73 Otero, Hernán: "El crecimiento de la población y la transición demográfica", en Susana Torrado (comp.): Población y bienestar en la Argentina del primer al segundo centenario Una historia social del siglo XX. T. I, Buenos Aires, Edhasa, 2007, p. 347.

74 Bertoni, Lilia Ana: Patriotas, cosmopolitas y nacionalistas: la construcción de la nacionalidad argentina a fines del siglo XIX, Buenos Aires, Fondo de Cultura Económica, 2001.

75 "Acción social", Boletín de la Y.M.C.A, 5 (1916), p. 3.

76 "Trabajando en pro de los padres de los futuros argentinos", Boletín de la Asociación Cristiana de Jóvenes. Y.M.C.A, 7 (1925), p. 5.

77 Recchini de Lattes, Zulma y Lattes, Alfredo: La población de la Argentina, Buenos Aires, Indec, 1975, pp. 69-70. 


\section{Conclusión}

En su desarrollo local, las actividades de la ACJ guiadas por el objetivo de colocar a las juventudes en la agenda pública contribuyeron a canalizar y materializar una serie de prevenciones que comenzaban a formularse sobre estos sectores: el activismo y la radicalización política de las juventudes universitarias; las conductas modernas y licenciosas entre la población estudiantil o trabajadora; el desarrollo de la delincuencia y la ociosidad entre los pibes y jóvenes de los barrios, los desafíos que suponía el proceso inmigratorio, entre otras cuestiones. Entre estas prevenciones, de la mano de la cuestión sexual, la eugenesia y la elaboración de teorías sobre la adolescencia y la pubertad, aquellas referidas a lo que se consideraba el correcto desarrollo de la virilidad y de la futura descendencia constituyen factores que consideramos cruciales para la comprensión de las representaciones sobre las juventudes en este periodo. Junto con ello, resulta imprescindible el contraste con las experiencias e identidades de quienes portaban o rechazaban para si dichas representaciones. Así, señalar las distancias entre el modelo de la ACJ y las identificaciones juvenilitas de estudiantes reformistas y no reformistas, por un lado, y aquellas que construían las juventudes de los barrios en torno al futbol, por el otro, permitió dar cuenta no solo de la dimensión heterogénea y plural de las juventudes, en tanto categoría histórica, sino también de las luchas simbólicas y resistencias que se operaban en ese proceso de clasificación a través de interacciones de la vida cotidiana.

Tras su consolidación interna, a partir de la segunda década del siglo, la ACJ buscó desarrollar una proyección social extendiendo su convocatoria juvenil más allá de los sectores que componían su membresía original. Para ello, al difundir sus categorías etáreas, que identificaban la juventud por fuera del umbral de la edad escolar obligatoria, y al dirigirse a un público que se perfilaba o que se intentaba encuadrar laboralmente, la asocicion incursionaba en un campo que afirmaba como descuidado y que por lo tanto debía constituirse como objeto de intervención y de atención dentro de la agenda pública. Sin embargo, pese a esa vocación abarcartiva la representación de un público juvenil se configuró desde limitaciones precisas. Por un lado, desde la divulgación de prácticas y valores de la cultura física la representación de lo juvenil quedaba atada a ciertos esteretipos de la masculinidad difundidos en el medio local por las clases altas y por heterogénos sectores que no se definían aun claramente desde una identidad de "clase media". Por otro lado, al apelar a la noción y a la configuración de liderazgos para la socialización de saberes y prácticas entre las juventudes de los sectores populares, la ACJ combinaba elementos de una representación (arraigada en el ámbito universitario local y difundida a través de una tradición literaria y ensayística) que ubicaba a los la población estudiantil universitaria como futura clase dirigente. Con cual, desde la noción de liderazgo cristiano se prentedía conducir a estos sectores a través de ciertas modalidadades de intervención pública (el estudio de problemas sociales o la obra en los barrios), que constrastaban con las prácticas, resignificaciones e inclusive rechazos que elaboraban las mismas juventudes universitarias de dicha misión dirigente.

Finalmente, otro tipo de limitaciones resultaba de la extensión efectiva que podía tener esta conovocatoria en contraste con el papel preponderante que continuaba ocupando la infancia (público que al que también se orientó la ACJ) en las políticas públicas y con el mayor alcance de otras interpelaciones hacia las juventudes que circulaban en marcos institucionales como el ejército o la educación secundaria y 
universitaria (pese que aun estas últimas abarcaban a sectores minoritarios de la población). Sin embargo, tal como se despende del análisis desarrollado, la ACJ confluyó en varios aspectos con el proyecto pedagógico que se desarrollaba en la educación pública en temas como la difusión de hábitos y nociones higiénicas, la construcción de cuerpos y subjetividades masculinas y femeninas, la formación de la ciudadanía y la nacionalidad; entre otras cuestiones que resultaban centrales para el proyecto "civilizador" y para sortear los principales desafíos y efectos no deseados del desarrollo capitalista. En esta confluencia la ACJ se orientó especialmente a la difusión de los deportes y en la formación de cuadros profesionales para ese fin; en la socialización de nuevas formatos para la educación sexual y en otros aspectos novedosos como la difusión de pasatiempos y prácticas de ocio y consumo juveniles. Para lo cual contó al mismo tiempo con los soportes materiales y las redes de la asociación, en tanto movimiento de proyección internacional, y con los apoyos y la vinculación con grupos intelectuales locales. Considerar estas convergencias permite ubicar las representaciones sobre las juventudes dentro de un entramado complejo que incluye la circulación trasnacional de saberes y las prácticas y apropiaciones que se elaboraban en el marco local y que involucran una variedad de agentes provenitentes del ámbito público, el campo intelectual, las asociaciones civiles y del mismo campo juvenil que se buscaba convocar.

\section{Referencias bibliográficas}

\section{Fuentes}

Asociación Cristiana de Jóvenes: Iniciativa Universitaria, Buenos Aires, Asociación Cristiana de Jóvenes, 1909.

Asociación Cristiana de Jóvenes: $18^{\circ}$ informe anual del directorio de la Asociación cristiana de jóvenes de Buenos Aires, Buenos Aires, Asociación Cristiana de Jóvenes, 1919.

Asociación Cristiana de Jóvenes: Veinte y cinco años de acción en la Metrópoli Argentina. 1902-1927, Buenos Aires, Asociación Cristiana de Jóvenes,

Asociación Cristiana de Jóvenes, Boletín de la Y.M.C.A., Buenos Aires, (1916-1918).

Asociación Cristiana de Jóvenes, Boletín de la Asociación Cristiana de Jóvenes. Y.M.C.A., Buenos Aires, (1919-1930).

Cantón, Eliseo: "La colación de grados en la Facultad de Ciencias Médicas", Revista de la Universidad de Buenos Aires, XVII (1912), pp. 445-448.

Wegener, Hans: Nosotros los jóvenes. El problema sexual del joven soltero, Madrid, Daniel Jorro, Editor, 1910.

\section{Bibliografía}

Ablard, Jonathan: "The Barracks receives spoiler children and returns men": Debating Military Service, Masculinity and Nation-Building in Argentina, 1901-1930". The Americas, 74 3, (2017), pp. 1-31.

Adamovsky, Ezequiel: Historia de la clase media en la Argentina. Apogeo y decadencia de una ilusión, Buenos Aires, Planeta, 2010. (1ºd. 2009).

Agulhon, Maurice: El Círculo Burgués. La sociabilidad en Francia, 1810-1848, Buenos Aires, Siglo XXI, 2009. 
Anderson, Patricia: "Deporte y civismo femenino en la Asociación Cristiana Femenina de Buenos Aires, 1890-1940" en Pablo Scharagrodsky (coord.): Mujeres en movimiento: deporte, cultura fisica y femineidades, Argentina, 1870-1980, Buenos Aires, Prometeo, 2016, pp. 189-204.

Archetti, Eduardo: Masculinidades: futbol, tango y polo en la Argentina, Buenos Aires, Deldragón, 2016. (1ª ed. 1999).

Barrán, José Pedro: Historia de la sensibilidad en el Uruguay, Montevideo, Ediciones de la Banda Oriental, 2009. ( $1^{\text {a }}$ ed. 1994).

Becerra Solá, Malena: El museo social argentino (1910-1930). Cuestión social y redes internacionales de reforma, Tesis doctoral, Madrid, Universidad Autónoma de Madrid, 2015.

Bederman, Gail: Manliness and civilization: A cultural history of gender and race in the United States, 1880-1917, Chicago, University of Chicago Press, 1995.

Bertoni, Lilia Ana: Patriotas, cosmopolitas y nacionalistas: la construcción de la nacionalidad argentina a fines del siglo XIX, Buenos Aires, Fondo de Cultura Económica, 2001.

Biagini, Hugo: La contracultura juvenil. De la emancipación a los indignados, Buenos Aires, Capital Cultural, 2012.

Bisso, Andrés: "Las conmemoraciones del "Día" y la "Semana del Scout" en Argentina (1928-1941)", en María Paula Bontempo y Andrés Bisso (eds.): Infancias y juventudes en el siglo XX: política, instituciones estatales y sociabilidades, Buenos Aires, Teseo Press, 2019, pp. 119- 161.

Bontempo, María Paula y Bisso, Andrés (eds.): Infancias y juventudes en el siglo XX: política, instituciones estatales y sociabilidades, Buenos Aires, Teseo Press, 2019.

Bourdieu, Pierre: Las estrategias de la reproducción social, Buenos Aires, Siglo XXI, 2011.

Bourdieu, Pierre: La distinción. Criterios y bases sociales del gusto, Madrid, Taurus, 1998. ( $1^{\mathrm{a}}$ ed. 1979).

Buchbinder, Pablo: ¿Revolución en los claustros? La Reforma universitaria de 1918, Editorial Sudamericana, Buenos Aires, 2008.

Buchbinder, Pablo (dir.): Juventudes Universitarias en América Latina: ayer y hoy, Rosario, Universidad Nacional de Rosario, 2019.

Bustelo, Natalia: La reforma universitaria desde sus grupos y revistas. Una reconstrucción de los proyectos y las disputas del movimiento estudiantil porteño de las primeras décadas del siglo XX (1914-1928), Tesis doctoral, La Plata, Universidad Nacional de La Plata, 2015.

Bustelo, Natalia y Domínguez Rubio, Lucas: "Radicalizar la Reforma Universitaria. La fracción revolucionaria del movimiento estudiantil argentino, 1918-1922", Anuario Colombiano de Historia Social y de la Cultura, 2, (2017), pp. 31-62.

Carreño, Luciana: Los estudiantes universitarios en tiempos de reformas. Sociabilidad y vida estudiantil en la universidad porteña (1900-1930), Buenos Aires, Eudeba, 2020.

Carreras, Sandra y Barbara Potthast (eds.): Entre la familia, la sociedad y el Estado. Niños y jóvenes en América Latina (siglos XIX-XX), Madrid-Frankfurt, Iberoamericana-Vervuert, 2005.

Cremonte, Martín: El momento soreleano. Vitalismo, juvenilismo y fascismo en la revista Inicial (1923-1927), Tesis de maestría, Universidad Nacional de San Martín, Buenos Aires, 2018.

Dussel, Inés: "Víctor Mercante: La adolescencia como categoría escolar. La emergencia de una problematización", en Víctor Mercante: La crisis de la pubertad y sus consecuencias pedagógicas, La Plata, UNIPE-Editorial Universitaria, 2014, pp. 11-41. 
Frydenberg, Julio: Historia social del futbol: del amateurismo a la profesionalización Buenos Aires, Siglo XXI, 2011.

González Bernaldo de Quirós, Pilar: "La 'sociabilidad' y la historia política”, en Nuevo Mundo Mundos Nuevos, Ecole des Hautes Etudes en Sciences Sociales, (7). Disponible en: http://journals.openedition.org/nuevomundo/24082.

Graciano, Osvaldo: Entre la torre de marfil y el compromiso politico. Intelectuales de izquierda en la Argentina, 1918- 1955, Bernal, Universidad Nacional de Quilmes, 2008.

Grundy, Pamela y Rader, Benjamin: American Sports. From the Age of Folk Games to the Age of Televised Sport, New York, Routledge, 2016. (1 $\left.{ }^{\mathrm{a}} \mathrm{ed} .2004\right)$.

Hall, Donald: "Muscular Christianity: Reading and Writing the male social body", en Donald E. Hall (ed.) Muscular Christianity. Embodying the Victorian age, New York, Cambridge University Press, 2006, (1 ${ }^{\mathrm{a}}$ ed. 1994), pp- 3-16.

Heilbronner, Oded: "From a Culture for Youth to a Culture of Youth: Recent Trends in the Historiography of Western Youth Cultures", Contemporary European History, 4 (2008), pp. 575-591.

Jordan, Benjamin René: 'A Modest Manliness': The Boy Scouts of America and the Making of Modern Masculinity, 1910-1930, Tesis doctoral, San Diego, University of California San Diego, 2009.

Lesko, Nancy: Act your age! A Cultural Construction of Adolescence, New York, Routledge, 2012. (1 ${ }^{\mathrm{a}}$ ed. 2001).

Lionetti, Lucía: "Discursos, representaciones y prácticas educativas sobre el cuerpo de los escolares. Argentina en las primeras décadas del siglo XX", Cuadernos de Historia, 34 (2011), pp. 31-52.

Lionetti, Lucía, Cosse, Isabella y Zapiola, M. Carolina (comps.): La historia de las infancias en América Latina, Tandil, Universidad Nacional del Centro de la Provincia de Buenos Aires, 2018.

Losada, Leandro: "Convenciones culturales y estilos de vida. La elite social de la Argentina de entreguerras en las crónicas sociales de la revista Caras y Caretas (1917-1939)", Social and Education History, 2 (2013), pp. 152-175.

Macleod, David: Building character in the American boy: The Boy Scouts, YMCA, and their forerunners, 1870-1920, Madison, University of Wisconsin Press, 1983.

Marsiske, Renate (coord.): Movimientos estudiantiles en la historia de América Latina V, Mexico D.F, Universidad Nacional Autónoma de México, Instituto de Investigaciones sobre la Universidad y la Educación, 2017.

Mosse, George: The image of man. The creation of modern masculinity, New York, Oxford University Press, 1996.

Ortemberg, Pablo (dir.): Dossier: "Panamericanismo, hispanoamericanismo y nacionalismo en los festejos identitarios de américa latina, 1880-1920. Performances y encrucijadas de diplomáticos e intelectuales", Anuario IHES, 32 (2017), pp. 99-110.

Otero, Hernán: "El crecimiento de la población y la transición demográfica", en Susana Torrado (comp.): Población y bienestar en la Argentina del primer al segundo centenario Una historia social del siglo XX. T. I, Buenos Aires, Edhasa, 2007, pp. 339- 367.

Pérez Islas, José Antonio y Urteaga Castro- Pozo, Maritza. (coords.): Historias de los jóvenes en México. Su presencia en el siglo XX, México D.F, Instituto Mexicano de la Juventud, 2004.

Portantiero, Juan Carlos: Estudiantes y política en América Latina. El proceso de la Reforma Universitaria (1918-1938), México, Siglo XXI, 1978.

Queirolo, Graciela: "Género y sexualidad en tiempos de males venéreos (Buenos Aires, 1920-1940)”, Revista Nomadías, 17 (2013), pp. 67-87. 
Recchini de Lattes, Zulma y Lattes, Alfredo: La población de la Argentina, Buenos Aires, Indec, 1975.

Scharagrodsky, Pablo: "El scautismo en la educación física bonaerense o acerca del buen encauzamiento varonil (1914-1916)", en Ángela Aisenstein y Pablo Scharagrodsky (dirs.): Tras las huellas de la educación física escolar argentina. Cuerpo, género y pedagogía. 1880-1950, Buenos Aires, Prometeo, 2006, pp. 135-158.

Silliti, Nicolás: "El Servicio Militar Obligatorio y la "cuestión social”: apuntes para la construcción de un problema historiográfico". Pasado Abierto, 7 (2018), pp. 265-275. Disponible en: http://fh.mdp.edu.ar/revistas/index.php/pasadoabierto/article/view/2570/2748.

Souto Kustrín, Sandra: "Historiografía y jóvenes: la conversión de la juventud en objeto de estudio historiográfico", Páginas, 22 (2018), pp. 16-38.

Vallejo, Gustavo: "La hora cero de la eugenesia en la Argentina: disputas e ideologías en el surgimiento de un campo científico, 1916-1932", História, Ciências, Saúde Manguinhos, 25 (2018), pp.15-32.

Vallejo, Gustavo: "El hombre nuevo: representaciones culturales en torno a la masculinidad en la Argentina (1918-1976)", Cuadernos de Historia Contemporánea, 40 (2018), pp. 89113.

Winter, Thomas: Making Men, Making Class: The YMCA and Workingmen, 1877-1920, Chicago, Chicago University Press, 2002. 
